\title{
Non-Cardiac Chest Pain, CTCAE
}

National Cancer Institute

\section{Source}

National Cancer Institute. Non-Cardiac Chest Pain, CT CAE. NCI Thesaurus. Code

C143707.

A disorder characterized by a sensation of marked discomfort in the chest unrelated to a heart disorder. 